\title{
October 26 Highlights
}

\section{Expanding the molecular classification of dementias}

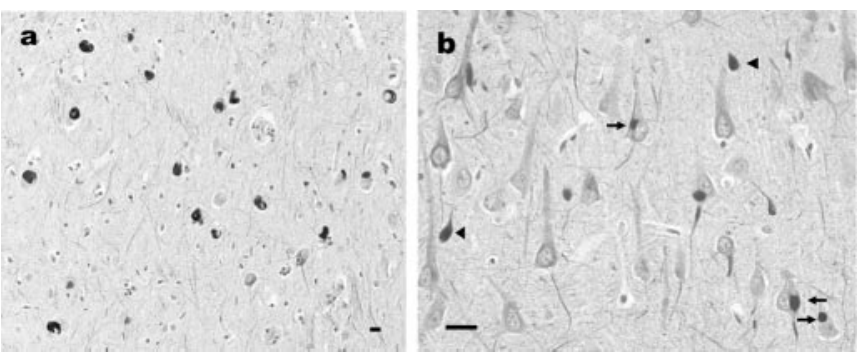

Neuronal IF inclusions in the temporal lobe. Subiculum (A) and pyramidal neurons (B, arrows) and swollen axons and spheroids (B, arrowheads).

Cairns et al. describe the clinical and neuropathologic features of 10 patients with neuronal intermediate filament inclusion disease (NIFID). Their cases have features of both frontotemporal dementia and motor neuron disease. Age at onset ranged from 23 to 56 years (mean 40.8) with a mean duration until death of 4.5 years.

see page 1376

The accompanying editorial by DeKosky and Ikonomovic notes that this article adds to the evidence that the most common mechanism of chronic neurodegenerative disorders involves abnormal protein production, processing, or misfolding, and subsequent accumulation in the brain. Specific neurons manifest selective vulnerability to specific protein processing abnormalities, for example, altered tau metabolism is associated with FTD AD, corticobasal degeneration, and progressive supranuclear palsy. In NIFID light, medium, and heavy (molecular weight) NF triplet proteins (NF-L, NF-M, and NF-H), a type $I V$ IF protein, and $\alpha$-internexin accumulate in a subset of patients with clinical features of FTD or CBD. Relatively young age at onset and faster progression of the disease, absence of family history of FTD, extrapyramidal symptomatology, diffuse hyperreflexia, and supranuclear ophthalmoplegia were suggestive of the diagnosis.

Thus, while NIFID may be an immunohistopathologically distinct form of FTD, its clinical manifestations are not unique. A biomarker is needed as well as an understanding of these mechanisms of NF aggregation.

\section{Prevalence of probable migraine in a health care plan}

Probable migraine (PM) is a migraine subtype lacking just one migraine feature. Patel et al. found that PM is as prevalent as migraine in a health plan and was associated with similar disability and impairment in quality of life.

see page 1432

\section{Cerebral vascularization configuration is associated with deep WMLs}

Van der Grond et al. found that vascular variations in the circle of Willis are independently associated with the deep WML load in the brain. A fetal configuration of the posterior part of the circle of Willis appeared to protect against WMLs.

see page 1452

\section{Peripheral neuropathy after gastric bypass surgery}

Bariatric gastric bypass surgery is being done increasingly to treat obesity. Thaisetthawatkul et al. characterized the neuropathy occurring after gastric bypass in 435 patients vs the neuropathy occurring after another abdominal surgery (cholecystectomy). Neuropathy occurred in $16 \%$ of patients vs only $3 \%$ of cholecystectomy controls. No specific subtype was identified: mononeuropathy, polyneuropathy, and radiculopathy all occurred.

see page 1462 


\section{The PINK1 gene in Irish Parkinson disease}

Mutations in the PINK1 gene, which encodes a mitochondrial protein, have recently been reported to cause autosomal recessive Parkinson disease. In this study, Healy et al. found a low prevalence of PINK1 mutations in a large sample of Irish Parkinson disease patients.

see page 1486

\section{$P A R K 6$-linked parkinsonism in Asian populations}

Hatano et al. report that eight families including three Japanese, two Taiwanese, one Turkish, one Israeli, and one Philippine showed evidence of linkage to PARK6, indicating its worldwide distribution.

see page 1482

The editorial by Andrew Singleton accompanying these two articles notes that there are now 10 PARK loci of which four have defined gene mutations associated with parkinsonism (PARK-1, -2, -6, and -7). PINK1 disease, like that caused by parkin mutation, is recessive, suggesting that loss of protein function is key. The pathogenic relevance of single heterozygous mutations as reported may remain a contentious issue. However, it is possible that the PINK1 mutation in the heterozygous state may lead to a dopaminergic deficit that predisposes to disease much as suggested in parkin heterozygotes.

see page 1350

\section{Considering measles SSPE in the differential diagnosis of encephalitis}

Honarmand et al. describe five cases of SSPE occurring in the 16,400 cases of the California Encephalitis Project. The diagnosis of SSPE was not considered by clinicians in three of the five cases-ADEM being mistakenly diagnosed.

see page 1489

The accompanying editorial by James Bale notes that measles is rare in the United States and SSPE, its most serious complication, occurs in $1 /$ million children. However, in many other countries, immunization is less widespread, leading to approximately 21 SSPE cases/million in India and about 100 cases/million in Papua New Guinea. The disorder is not treatable but is preventable by measles immunization (which does not cause SSPE itself).

\section{Safety of rapid infusion of valproate}

The open, dose-escalation study in epilepsy patients by Wheless et al. demonstrated that rapid infusion IV of valproate at rates up to $6 \mathrm{mg} / \mathrm{kg} / \mathrm{min}$ was well tolerated and caused no clinically important changes in blood pressure or pulse.

see page 1507

\section{Phenytoin generic gives lower levels than brand}

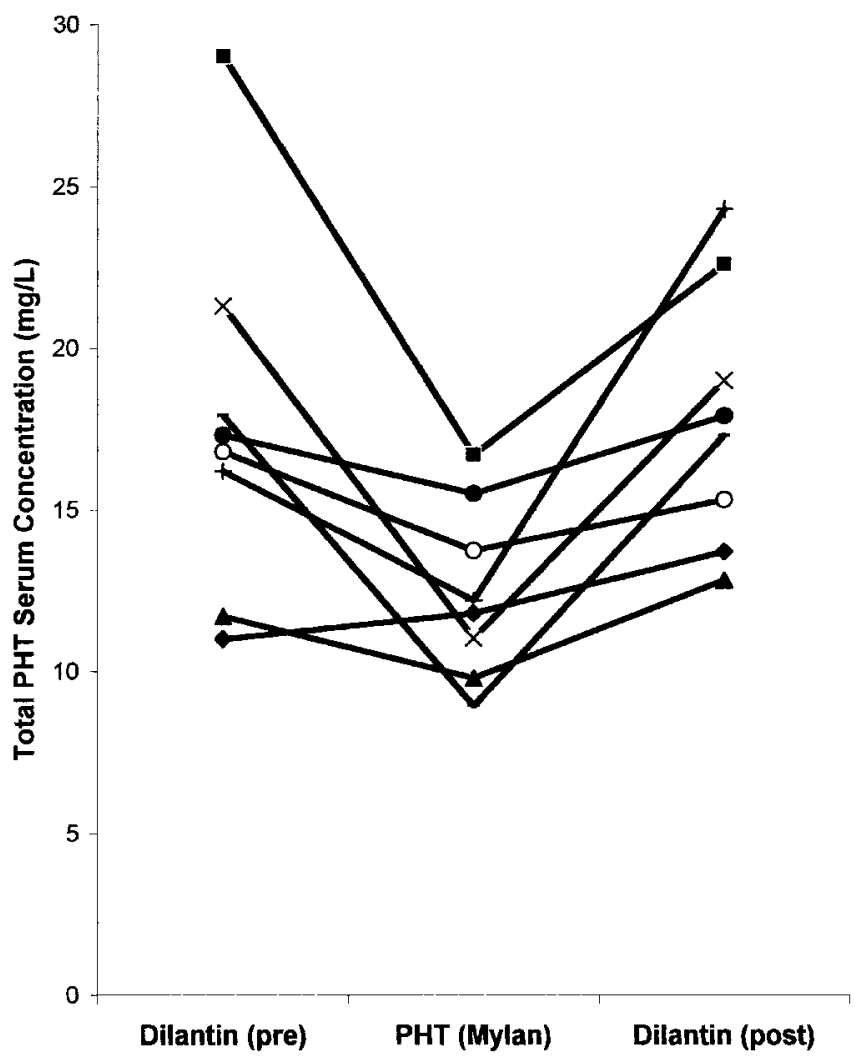

The FDA has considered brand and generic phenytoin equivalent. Burkhardt et al. found that in a clinical setting the small difference in bioavailability of phenytoin is magnified by non-linear kinetics. Their eight patients had a clinically important decrease in levels when switched to generic, which was reversed by restarting brand.

see page 1494 


\section{Neurology}

October 26 Highlights

Neurology 2004;63;1346-1347

DOI 10.1212/WNL.63.8.1346

This information is current as of October 25, 2004

\section{Updated Information \&} Services

Permissions \& Licensing

Reprints including high resolution figures, can be found at: http://n.neurology.org/content/63/8/1346.full

Information about reproducing this article in parts (figures,tables) or in its entirety can be found online at:

http://www.neurology.org/about/about_the_journal\#permissions

Information about ordering reprints can be found online:

http://n.neurology.org/subscribers/advertise

Neurology ${ }^{\circledR}$ is the official journal of the American Academy of Neurology. Published continuously since 1951, it is now a weekly with 48 issues per year. Copyright . All rights reserved. Print ISSN: 0028-3878. Online ISSN: 1526-632X.

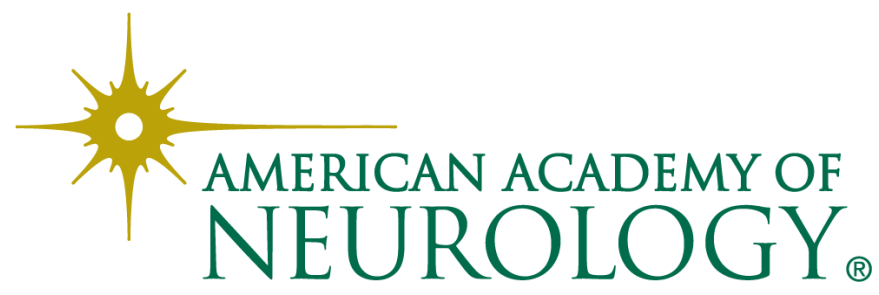

